\title{
Composition dependence of the synergistic effect of nucleating agent and plasticizer in poly(lactic acid): A Mixture Design study
}

\author{
M. K. Fehri ${ }^{1}$, C. Mugoni ${ }^{2}$, P. Cinelli ${ }^{1}$, I. Anguillesi $^{1}$, M. B. Coltelli ${ }^{1}$, S. Fiori ${ }^{3}$, M. Montorsi ${ }^{2}$, \\ A. Lazzeri ${ }^{1 *}$ \\ ${ }^{1}$ Inter University Consortium of Materials Science and Technology (INSTM) c/o University of Pisa, Department of Civil \\ and Industrial Engineering - DICI, Largo Lucio Lazzarino 1, 56122 Pisa, Italy \\ ${ }^{2}$ University of Modena and Reggio Emilia, Department of Engineering Sciences and Methods - DISMI, via Amendola 5, \\ 42122 Reggio Emilia, Italy \\ ${ }^{3}$ Condensia Química S.A, C/ La Cierva, 8; P.I.: Can Cortés, 08184 Palau-Solitá i Plegamans, Barcelona, Spain
}

Received 31 July 2015; accepted in revised form 19 October 2015

\begin{abstract}
Blends consisting of commercial poly(lactic acid) (PLA), poly(lactic acid) oligomer (OLA8) as plasticizer and a sulfonic salt of a phthalic ester and poly(D-lactic acid) as nucleating agents were prepared by melt extrusion, following a Mixture Design approach, in order to systematically study mechanical and thermal properties as a function of composition. The full investigation was carried out by differential scanning calorimetry (DSC), dynamic mechanical thermal analysis (DMTA) and tensile tests. The crystallization half-time was also studied at $105^{\circ} \mathrm{C}$ as a function of the blends composition. A range of compositions in which the plasticizer and the nucleation agent minimized the crystallization half-time in a synergistic way was clearly identified thanks to the application of the Mixture Design approach. The results allowed also the identification of a composition range to maximize the crystallinity developed during the rapid cooling below glass transition temperature in injection moulding, thus allowing an easier processing of PLA based materials. Moreover the mechanical properties were discussed by correlating them to the chemical structural features and thermal behaviour of blends.
\end{abstract}

Keywords: biodegradable polymers, mixture design, poly(lactic acid), plasticizer, nucleating agents

\section{Introduction}

For applications where selective collection and chemical-mechanical recycling are not economical or feasible, the use of some specific bio-polymers would enable bio-recycling, particularly in the field of packaging. During the last decade, among biodegradable and biocompatible polymers, Poly lactic acid (PLA) has been considered as a potential alternative for oil derived plastic materials on the basis of its good processability, and relatively low cost [1]. The commercial PLA consists mainly of L-lactic acid units but it contains a few percentage by weight of
D-lactic acid units. The content of D-lactic acid units in commercial PLA is different in dependence of the final specific grade, developed to fulfil the final application requirements. Although some modulation of properties was achieved by controlling the D-monomer content in the polymer, its applications are anyway limited by the low glass transition (about $60^{\circ} \mathrm{C}$ ), the brittleness, and the intrinsic low crystallization rate [2-6].

In order to overcome limitations in some properties, additives such as polymers $[7,8]$, fillers $[9,10]$ or plasticizers can be used also in combination $[11,12]$.

\footnotetext{
${ }^{*}$ Corresponding author, e-mail: a.lazzeri@ing.unipi.it

(C) BME-PT
} 
Plasticizers such as poly (ethylene glycol) [13], oligomeric lactic acid $[14,15]$, citrate esters [16] are frequently used to tune PLA mechanical properties increasing its ductility. In terms of thermal properties the addition of a plasticizer usually results in a strong increase in spherulitic growth rate with respect to pure PLA. The effect of plasticization was also studied in PLA based blends by Quero et al. [17]. They studied the effect on PLA crystallization rate of the acetyl tri-n-butyl citrate (ATBC) plasticizer and of poly(butylene adipate-co-terephthalate) (PBAT). The addition of the plasticizer resulted in a decrease in glass transition temperature of PLA. However the addition of increasing amount of PBAT resulted in an increase in PLA glass transition temperature as a consequence of preferential migration of ATBC in the PBAT phase [16] and a general synergistic effect was evidenced on the overall crystallization rate of the PLA component when both PBAT and ATBC were added to PLA.

In the industrial production usually PLA is melt processed and then rapidly cooled [2] below its glass transition temperature. As the crystallization of PLA is slow, final products (such as injection moulded or blow moulded parts or containers) are mainly amorphous. Thus the increase of temperature above PLA glass transition during the further processing steps (e.g. in the packaging of hot products) or during the use of the material, can enable cold crystallization, resulting in undesired shrinkages leading to dimension instability and deformation of the items. In addition, an increase in brittleness and change in optical properties can be observed as a consequence of crystallinity increase. In particular, for packaging of 'hot-filled' food or beverage bottles or other containers, i.e. filled at the food-manufacturing or beveragebottling plant while the food or beverage is still hot from pasteurization, amorphous PLA is not suitable. Thus the use of proper nucleating agents, allowing increasing the crystallization rate of PLA during the rapid cooling is particularly interesting on a technological point of view. In PLA $[18,19]$ nucleating agents are reported to much affect the crystallinity content because they promote the formation of a high number of crystallization nuclei, thus consequently influencing also crystal growth and transparency [20]. Nucleated PLA thus results stabilized and its optical and mechanical properties are not modified as a consequence of heating in the temperature range of its glass transition.
Much attention is thus devoted to PLA nucleating agents, organic [21-23], such as sodium benzoate, or inorganic, such as calcium carbonate, talc, boron nitride $[24,25]$ to better tune crystallization rate and final crystallinity content. Nano-fillers, such as cellulose nano-whiskers [26], carbon nano-tubes [27] or graphene oxide [28] were also reported to act as nucleating agents for PLA, although composition and geometrical characteristics of the nano-fillers were reported to have a strong effect on overall crystallization rate. In general, a planar structure in organic molecules or rigid surface in nano-fillers and also groups interacting with polyester chains (also leading to chain scission [21]) are characteristics typical of all the effective nucleating agents, indicating that both the formation of specific directional linkages or confinement effects can affect the mobility and orientation at a molecular scale, thus influencing crystals formation.

Interestingly the effect of a plasticizer and a nucleating agent can be combined [29, 30]. For instance You et al. [31] used dibenzylidene sorbitol as organic nucleant agent, PEG as plasticizer and a multifunctional reactive molecule. Dibenzylidene sorbitol nanofibrils formed in the PEG gel, could supply active nucleating sites for PLA when the gel is added in PLA. The reactive molecules can introduce extra interaction between PLA macromolecules and Dibenzylidene sorbitol nanofibrils, which makes the nucleation easier and faster. Yu et al. [32] studied the cold crystallization of materials based on PLA containing talc and plasticized with compressed carbon dioxide. They reported that a plasticizer can increase the crystallization rate through accelerating the spherulite growth rate thanks to the increased mobility of the polymeric chains, while a nucleating agent can enhance the crystallization rate by increasing the nuclei density. Li and Huneault [33] investigated the combined effect of both plasticizer (acetyl triethyl citrate) and nucleating agents (talc, sodium stearate and calcium lactate) on mechanical and thermal properties of PLA. In the non-isothermal DSC experiments, the crystallinity developed upon cooling was systematically studied at different cooling rates. The non-isothermal data showed that the combination of nucleating agent and plasticizer is necessary to develop significant crystallinity at high cooling rates. A sort of synergy was thus observed, but the composition range in which this synergy can be obtained and the trend of properties as a function of 
composition of the ternary systems was not determined in a systematic way.

Oligomeric poly(lactic acid)s are newly conceived plasticizers developed for the plasticization of PLA and biodegradable polymers obtained from biorenewable raw materials and fully biodegradable and bio disposable. When they are used in PLA they allow obtaining stretched films with excellent mechanical properties without loss of transparency $[14,15]$. However their effect combined with nucleating agents has never been studied.

In the field of nucleating agents the commercial product LAK (an aromatic sulfonate) is reported to provide a high crystallinity, high heat-stability of PLA mould parts and allows the onset of cold crystallization beginning at higher temperature [34]. PDLA was also found to behave as a nucleating agent for decreasing the half-time of crystallization [35] of PLA, with the advantage of the excellent compatibility because of the much similar structure and also thanks to the formation of stereocomplexes [36, 37]. More recently Shi et al. [38] evidenced again the synergistic effect of nucleating agents and plasticizer by plasticizing PLA with PEG and adding also different nucleating agents such as PDLA, LAK and talc. LAK and PDLA effects were reported to be different and both promising because LAK showed an effective promotion of PLA crystallization behavior due to heterogeneous nucleation, while the addition of PDLA to PLA resulted in the formation of PLA stereocomplexes, acting as another type of nucleation process. In the paper of Shi et al. [38] a combination of LAK as nucleation agent and talc, used also as reinforcing filler, was reported to allow a good combination of properties, as the crystallization half-time was reduced and, regarding the mechanical properties, an improved ductility of the material was attained. However, any evidence about what can be the trend of thermal and mechanical behaviour as a function of composition was not reported.

The present work, is devoted to investigate the use of a biodegradable plasticizer Glyplast OLA8 (OLA8) based on oligomeric PLA, in combination with nucleating agents, poly(D-lactic acid) (PDLA) or LAK301 (LAK), in PLA formulation in order to improve the mechanical and thermal properties of PLA controlling its processing. In particular, in order to systematically study this system as a function of composition, in the present study the effects of four mixture components PLA, OLA8 (as plasticizer) and LAK and
PDLA (as nucleating agents) on the thermal and mechanical properties of the blends were investigated by using multivariate statistical methods which allowed identifying the compositional region where the crystallization rate is maximized and where a synergistic effect between plasticizer and nucleation agents can be observed. The work was planned using an extension of the Design of Experiments (DoE) method called Mixture Design approach, in which the weight fraction of formulations components constitute the input factors. DoE represents a very important tool complementary to the traditional approaches (based on one factor variation at a time) in order to improve the performances of the process correlated both to the material design and to its synthesis [39]. Specifically, the Mixture Design considers the different components of formulation as not completely independent from each other, allowing estimating how the ratios between ones to each other directly affect the target properties [40].

\section{Experimental section}

\subsection{Materials and methods}

PLA NatureWorks LLC INGEO 2003D, (average molecular weight 200000 , melting point temperature $T_{\mathrm{m}}=160^{\circ} \mathrm{C}$, glass temperature $T_{\mathrm{g}}=55-58^{\circ} \mathrm{C}$; D-lactic acid content in the range 4-4,5\% [41]) has been used. The plasticizer Glyplast OLA8 (Figure 1), an alkyl terminated oligoester of lactic acid, and the PDLA were provided by Condensia Quimica, Spain. LAK-301 (LAK) is an aromatic sulfonate derivative produced by Takemoto oil\&fat Co.Lt, Japan and currently employed in Ingeo(TM) 3801X (NatureWorks, PLA resin) formulation as nucleating agent. The blends extrusion was carried out in a Haake Minilab at $180^{\circ} \mathrm{C}, 90 \mathrm{rpm}$, recovering the molten material after $1 \mathrm{~min}$ of recirculating time. The start-

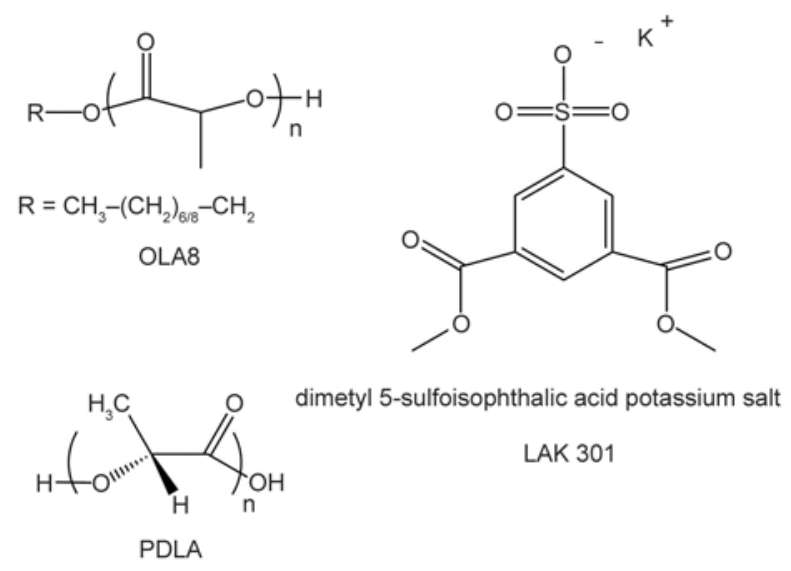

Figure 1. Structure of the additives used in this work 
ing polymers were previously dried at $60^{\circ} \mathrm{C}$ in vacuum for four days. After extrusion, the molten materials were transferred through a preheated cylinder to the Haake MiniJet II mini injection moulder (Thermo Scientific Haake GmbH, Karlsruhe, Germany), operating at 650 bar pressure, mould temperature of $35^{\circ} \mathrm{C}$, for $15 \mathrm{sec}$, to obtain Haake type 3 specimens (557-2290) used for measurements and analysis. The specimens were placed in plastic bags for vacuum sealing to prevent moisture absorption. Tensile tests were carried out on an Instron 5500R universal testing machine at $10 \mathrm{~mm} / \mathrm{min}$ with a load cell of $1 \mathrm{kN}$. By this tests the elastic modulus $(E)$, the stress at break $\left(\sigma_{\mathrm{b}}\right)$, the yield stress $\left(\sigma_{\mathrm{y}}\right)$ and the elongation at break $\left(\varepsilon_{\mathrm{b}}\right)$ were determined.

DSC measurements for determining the thermal properties and time of crystallization were carried out on a DSC Q200 TA instrument, setting a first run from $20^{\circ} \mathrm{C}$ to 190 at $10^{\circ} \mathrm{C} / \mathrm{min}$, an isothermal step of $5 \mathrm{~min}$ at $190^{\circ} \mathrm{C}$, a fast cooling step to $105^{\circ} \mathrm{C}$, and an isothermal step at $105^{\circ} \mathrm{C}$ for $30 \mathrm{~min}$. The latter step was performed to measure the crystallization half-time $t_{1 / 2}$, since it has to be at least three times longer than the time required for crystallization. Finally the sample is heated up to $190^{\circ} \mathrm{C}$ at $10^{\circ} \mathrm{C} / \mathrm{min}$.

The blends crystallinity, developed during the rapid cooling ( 15 seconds) in the mini injection moulder, is determined by calculating the difference $\left(\Delta H_{\mathrm{m}}\right)$ between the area under the melting peak and the area under the cold crystallization peak. Thus the crystallinity of PLA ( $\%$ cryst. I) was determined according to Equation (1):

$\%$ cryst. I. $=\frac{\Delta H_{\mathrm{m}}}{\Delta H_{100 \% \mathrm{C}}} \cdot 100$

where $\Delta H_{100 \% \mathrm{C}}$ is the melting enthalpy of $100 \%$ crystalline PLA $(93.0 \mathrm{~J} / \mathrm{g})$.

From the thermogram of the final heating step the area of the melting peak $(\Delta H)$ and the percentage of crystallinity developed after the isothermal process (\% cryst. II) were also calculated.

Dynamic mechanical thermal analysis was performed on a GABO Eplexor 100N Instrument, working in tensile mode, on $20 \times 5 \mathrm{~mm}$ specimen cut from the Haake type 3 specimens, with an average thickness of $1.6 \mathrm{~mm}$, at a heating rate of $2^{\circ} \mathrm{C} / \mathrm{min}$, from -100 to $150^{\circ} \mathrm{C}$, and $1 \mathrm{~Hz}$ frequency. By means of the dynamic mechanical thermal the glass transition temperature was determined.
The compositions investigated in this study were planned by using the Mixture Design in which two main constrains were used: the first regarding the proportion of the constituent proportion $x_{\mathrm{i}}$ in the mixture (Equation (2)):

$0 \leq x_{\mathrm{i}} \leq 1, \quad i=1,2,3 \ldots q, \quad \sum_{\mathrm{i}=1}^{\mathrm{q}} x_{\mathrm{i}}=1$

where $q$ are the constituents. The second regards the additional boundary constrains on the constituent proportion.

In mixture design, there are some additional boundary constraints on the constituents proportion $\left(x_{\mathrm{i}}\right)$, which limit the feasible space of components between the lower $\left(L_{\mathrm{i}}\right)$ and the upper $\left(U_{\mathrm{i}}\right)$ constraints. The general form of the constrained mixture problem is given by (Equation (3)):

$i=1,2,3, \ldots . Q, \quad 0<L_{\mathrm{i}}<x_{\mathrm{i}}<U_{\mathrm{i}}<1$

Restrictions reported in Equation (3) reduce the constraint region given by Equation (2) to an irregular dimensional space.

Mixture models, most commonly used in fitting data, are the functions known as the Scheffé canonical [37] polynomials (Equation (4)) and given by:

$E(Y)=\sum_{\mathrm{i}=1}^{\mathrm{q}} \beta_{\mathrm{i}} x_{\mathrm{i}}+\sum_{\mathrm{i}<\mathrm{j}}^{\mathrm{q}} \sum^{\mathrm{q}} \beta_{\mathrm{ij}} x_{\mathrm{i}} x_{\mathrm{j}}$

where $E(Y)$ is the response, $\beta_{\mathrm{i}}$ and $\beta_{\mathrm{ij}}$ are the regression coefficients calculated from the experimental data by multiple regression, and $x_{\mathrm{i}}$ and $x_{\mathrm{j}}$ are the levels of the independent variables. Table 1 reports the components considered in this work and their specific range.

The resulting experimental region is an irregular polyhedron, thus the mixture components were transformed in U-Pseudo components (reported in Table 1 as Low and High coded), where the maximum value of each component becomes zero and the minimum value approaches one, according to equation reported in literature $[40,42]$.

Table 1. Composition data and their ranges

\begin{tabular}{|c|l|c|c|c|c|}
\hline Component & Name & $\begin{array}{c}\text { Low } \\
\text { actual }\end{array}$ & $\begin{array}{c}\text { High } \\
\text { actual }\end{array}$ & $\begin{array}{c}\text { Low } \\
\text { coded }\end{array}$ & $\begin{array}{c}\text { High } \\
\text { coded }\end{array}$ \\
\hline A & OLA8 & 0.05 & 0.20 & 0.750 & 0 \\
\hline B & PLA & 0.7 & 0.90 & 1.000 & 0 \\
\hline C & LAK & 0 & 0.05 & 0.250 & 0 \\
\hline D & PDLA & 0 & 0.05 & 0.250 & 0 \\
\hline
\end{tabular}


Table 2. Experimental plan

\begin{tabular}{|c|c|c|l|l|l|}
\hline Sample & Order of run & OLA 8 & POLY L & LAK & PDLA \\
\hline 1 & 11 & 0.066 & 0.834 & 0.05 & 0.05 \\
\hline 2 & 2 & 0.200 & 0.700 & 0.05 & 0.05 \\
\hline 3 & 7 & 0.100 & 0.900 & 0 & 0 \\
\hline 4 & 6 & 0.138 & 0.812 & 0 & 0.05 \\
\hline 5 & 4 & 0.200 & 0.722 & 0.028 & 0.05 \\
\hline 6 & 14 & 0.200 & 0.782 & 0 & 0.018 \\
\hline 7 & 10 & 0.200 & 0.750 & 0.05 & 0 \\
\hline 8 & 15 & 0.133 & 0.805 & 0.037 & 0.025 \\
\hline 9 & 8 & 0.056 & 0.900 & 0.009 & 0.035 \\
\hline 10 & 3 & 0.055 & 0.890 & 0.05 & 0.005 \\
\hline 11 & 1 & 0.129 & 0.820 & 0.026 & 0.026 \\
\hline 12 & 5 & 0.129 & 0.820 & 0.026 & 0.026 \\
\hline 13 & 9 & 0.129 & 0.820 & 0.026 & 0.026 \\
\hline 14 & 12 & 0.129 & 0.820 & 0.026 & 0.026 \\
\hline 15 & 13 & 0.129 & 0.820 & 0.026 & 0.026 \\
\hline 16 & 16 & 0.200 & 0.782 & 0 & 0.018 \\
\hline
\end{tabular}

Sixteen experiments, including five center points (that are also replicated points) were planned as detailed in Table 2. The experiments were performed according to the randomized run order. In most of the tested formulations LAK and PDLA were simultaneously present.

For $E, \sigma_{\mathrm{b}}, \sigma_{\mathrm{y}}, T_{\mathrm{g}}, t_{1 / 2}, \%$ cryst I, $\%$ cryst II and $\Delta H$ different models were analyzed and their validity were ascertained through the ANOVA analysis by using commercially available software (Design Expert 7, Stat-Ease). The resulting models allowed describing the relationships between the starting composition and the final measured responses.

\subsection{Data analysis}

The regression analysis of the data was conducted by the analysis of variance called ANOVA. It is a statistical method in which two F-tests (F-test of the model and lack of fit test) were used to assess the validity of the model [40, 42].

The residual analysis is generally used to point out potential deviating experiments. The regression coefficients of the model were analysed and all the terms with a $p$-value higher than 0.05 were not considered as statically significant and therefore neglected in the model formulation. The trace and the response contour plots are used for a deeper explanation of the role of the mixture components on the final properties. The interpretation of these plots is strongly connected to the use of U-pseudo components used in this work.

In detail, the trace plot shows the effects of changing each component (main effect) along an imaginary line from the reference blend (defaulted the center point) to the vertex. In this plot, the effect ( $y$-axis) produced by the factor variation ( $x$-axis) should be interpreted considering that each component is at the lower real value in the right side of the $x$-axis, and it is at the higher real value in the left side of the same axis. Generally, the graph lines explain the effect of each component on the analysed response; a horizontal line (the slope is zero) implicates that the response value does not change varying the amount of a component while linear or parabolic trend indicates a strong variation of the response value (keeping the ratio on the proportions of the remaining components constant at the reference mixture) depending by the composition [38]. The response contour plot shows graphically the obtained results also in terms of interactions and quadratic effects and it is also helpful for choosing the best point at which the desired final properties can be satisfied (optimization perspective). In the contour plot the amount of each factor changes in the opposite way with respect to the usual one in simplex lattice design [38].

\section{Results and discussion}

\subsection{Mechanical properties}

The experimental results of tensile tests $\left(E, \sigma_{\mathrm{y}}, \varepsilon_{\mathrm{y}}, \sigma_{\mathrm{b}}\right.$, $\left.\varepsilon_{\mathrm{b}}\right)$ and dynamic thermal mechanical analysis $\left(T_{\mathrm{g}}\right)$ are reported in Table 3.

A general good reproducibility of the experimental data is observed, because, especially for the $E, \sigma_{\mathrm{b}}, \sigma_{\mathrm{y}}$

Table 3. Results of mechanical tests and dynamic thermal mechanical analysis

\begin{tabular}{|c|c|c|c|c|c|c|}
\hline \multirow{2}{*}{ Sample } & \multicolumn{5}{|c|}{ Mechanical properties } & DMTA \\
\cline { 2 - 7 } & $\begin{array}{c}\boldsymbol{E} \\
{[\mathbf{G P a}]}\end{array}$ & $\begin{array}{c}\boldsymbol{\sigma}_{\mathbf{y}} \\
{[\mathbf{M P a}]}\end{array}$ & $\begin{array}{c}\boldsymbol{\varepsilon}_{\mathbf{y}} \\
{[\mathbf{\%}]}\end{array}$ & $\begin{array}{c}\boldsymbol{\sigma}_{\mathbf{b}} \\
{[\mathbf{M P a}]}\end{array}$ & $\begin{array}{c}\boldsymbol{\varepsilon}_{\mathbf{b}} \\
{[\%]}\end{array}$ & $\begin{array}{c}\boldsymbol{T}_{\mathbf{g}} \\
{\left[{ }^{\circ} \mathbf{C}\right]}\end{array}$ \\
\hline 1 & 2.6 & 47 & 2.2 & 40 & 8.6 & 57 \\
\hline 2 & 1.2 & 11 & 3.5 & 20 & 278 & 45 \\
\hline 3 & 2.7 & 47 & 1.9 & 38 & 5.6 & 57 \\
\hline 4 & 2.1 & 42 & 2.3 & 32 & 5.3 & 53 \\
\hline 5 & 2.0 & 18 & 2.9 & 23 & 285 & 45 \\
\hline 6 & 1.7 & 17 & 2.8 & 28 & 340 & 47 \\
\hline 7 & 2.2 & 28 & 2.2 & 18 & 247 & 47 \\
\hline 8 & 3.1 & 41 & 2.0 & 31 & 15.3 & 53 \\
\hline 9 & 3.1 & 50 & 2.1 & 39 & 11.0 & 61 \\
\hline 10 & 3.2 & 36 & 1.7 & 28 & 9.2 & 63 \\
\hline 11 & 2.6 & 39 & 2.2 & 31 & 9.5 & 53 \\
\hline 12 & 2.5 & 42 & 2.2 & 32 & 13.5 & 53 \\
\hline 13 & 2.8 & 40 & 1.8 & 20 & 15.5 & 55 \\
\hline 14 & 2.8 & 38 & 1.9 & 30 & 9.0 & 51 \\
\hline 15 & 2.7 & 40 & 1.8 & 30 & 10.5 & 53 \\
\hline 16 & 1.2 & 16 & 2.5 & 23 & 310 & 47 \\
\hline
\end{tabular}

$E$ : Young's modulus, $\sigma_{\mathrm{y}}$ : yield stress, $\varepsilon_{\mathrm{y}}$ : elongation at yield, $\sigma_{\mathrm{b}}$ : stress at break, $\varepsilon_{\mathrm{b}}$ : elongation at break, $T_{\mathrm{g}}$ : glass transition temperature 
the values corresponding to the replicated tests (11, $12,13,14,15$, and 6,16$)$ are close to each other with a low variation compared to the variation of the entire data.

During the tensile test, all samples showed yielding, flow softening and even strain hardening. After yielding, on the specimen, a necking zone was observed and the neck extended until final fracture.

The effect of the selected input factors on the mechanical properties can be described using a linear model for $E$ and $\sigma_{\mathrm{b}}$, and a quadratic one for $\sigma_{\mathrm{y}}$. The experiment 10 is not used in the data analysis of both $\sigma_{\mathrm{b}}$ and $\sigma_{\mathrm{y}}$ since it was highlighted as deviating experiments.

Table 4 summarizes the ANOVA results for each model.

The $F$-values are higher than one $(p$-value $<0.05)$, and the Lack of Fit is not significant ( $p$-value $>0.05$ ), thus satisfying the two F-tests. Moreover $R$-Squared, Adj R-Squared and Pred R-Squared for $\sigma_{\mathrm{b}}$ and $\sigma_{\mathrm{y}}$ are higher than 0.8 pointing out the validity of the model. On the contrary the ANOVA parameters for $E$ are not excellent and particularly the Pred $R$ Squared value (0.51) clearly suggests that a more complex model should be developed in order to ensure an appropriate prediction power. Anyway, the aim of this work is mainly focused on a screening perspective, therefore all the models (including that for $E$ ) can be used to describe quantitatively and for $E$ just qualitatively, the effect of the blend compositions on the mechanical properties.

Moreover, further analysis of the model coefficients (not reported in this work) suggests that only OLA8 and PLA play a significant role on elastic modulus $E$ excluding any influence of both LAK and PDLA. The trace (reported as example of a trace plot) and contour plots reported in Figure 2a and $2 \mathrm{~b}$ respectively, show in detail the influence of each factor on $E$. The first one (Figure 2a) clearly points out that decreasing the amount of OLA8 (from the left to the right side of the plot) the modulus of elasticity increases, while PLA produces the opposite effect. The same information can be also derived from the contour plot reported in Figure 2b. The correlation between $E$ and the OLA8 content is in agreement with the plasticizing effect of this additive.

For the yield stress $\left(\sigma_{\mathrm{y}}\right)$ the overall results of the statistical analysis reveals that a decrease in PLA and LAK content leads to a decrease in $\sigma_{\mathrm{y}}$, while by decreasing OLA8 and PDLA the $\sigma_{\mathrm{y}}$ value increases. For this properties the presence of quadratic terms in the model has been observed and among them the LAK*PDLA is the most significant one. Moreover, it is worth noting that the highest amount of LAK and the lowest amount of PDLA leads to the highest value of $\sigma_{\mathrm{y}}$, as illustrated in Figure 3 (two components mix

Table 4. ANOVA results for the mechanical properties: modulus of elasticity $(E)$, stress at break $\left(\sigma_{\mathrm{b}}\right)$, yield stress $\left(\sigma_{\mathrm{y}}\right)$

\begin{tabular}{|l|c|c|c|c|c|c|c|}
\hline & $\boldsymbol{F}$-value & $\boldsymbol{p}_{\text {-value }}^{\mathrm{a}}$ & Lack of fit & $\boldsymbol{p}_{\text {-value }}^{\mathrm{b}}$ & $\boldsymbol{R}$-Squared & Adj $\boldsymbol{R}$-Squared & Pred R-Squared \\
\hline$E$ & 11.70 & 0.0007 & 4.79 & 0.052 & 0.75 & 0.69 & 0.51 \\
\hline$\sigma_{\mathrm{b}}$ & 47.30 & $<0.0001$ & 1.46 & 0.350 & 0.93 & 0.91 & 0.82 \\
\hline$\sigma_{\mathrm{y}}$ & 168.32 & $<0.0001$ & 1.16 & 0.390 & 0.99 & 0.99 & 0.93 \\
\hline
\end{tabular}

${ }^{a} p$-value associated to the F-Test of the regression model

${ }^{\mathrm{b}} p$-value associated to the lack of fit test
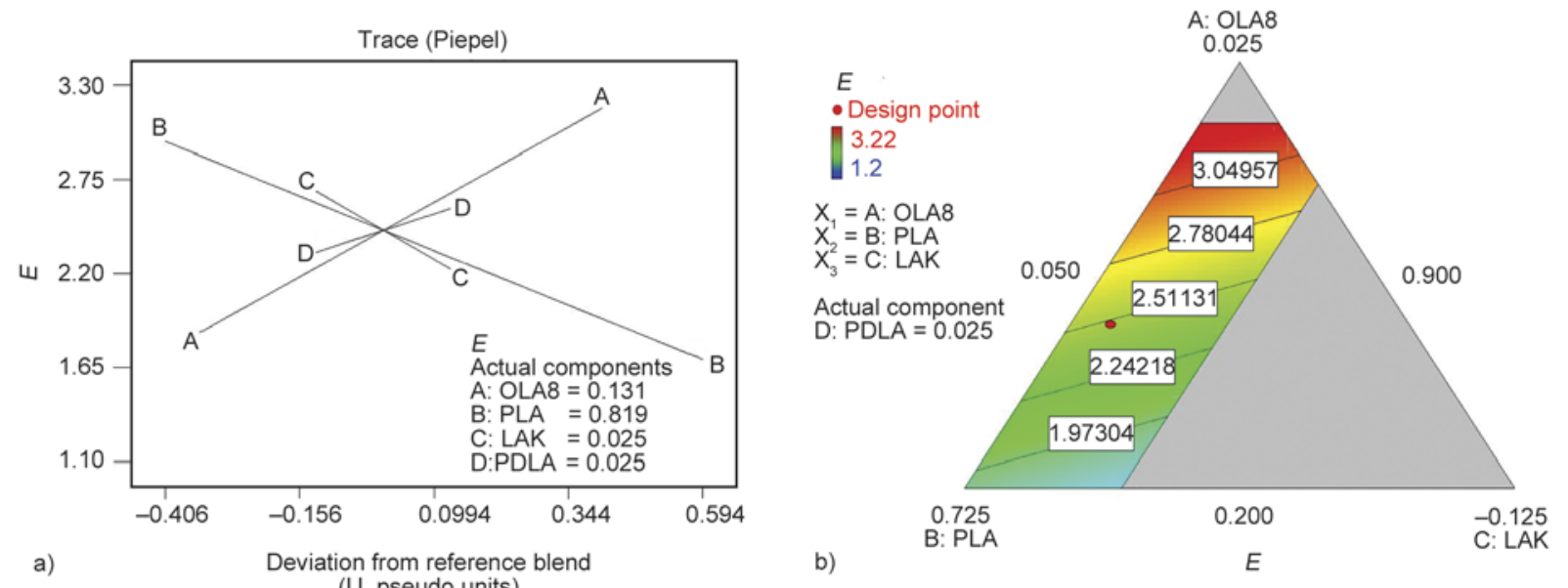

Figure 2. Trace (a) and contour plot (b) of $E$ 
graph). Possible explanation of the correlation between PDLA content and $\sigma_{\mathrm{y}}$ can be derived considering that this component in the blend can promote stereo complexes formation as detailed by Wei et al. [35]. In general, when PLLA/PDLA 1:1 solution casted blend are prepared the tensile properties $E, \sigma_{\mathrm{y}}$ and $\sigma_{\mathrm{b}}$ increase [36], because the formation of these complexes inside the blend structure leads to an increased structural rigidity due to the formation of a branched/crosslinked system but when the content of PDLA is lower in melt processed blend a decrease in these properties was recently observed [44, 45]. Probably the melt extrusion, having a short residence time, cannot allow an optimal dispersion of PDLA in PLA. In general, in PLA containing less than $10 \%$ of PDLA prepared in the melt, an effect onto crystallization behaviour and melt viscosity [46] of the formation of stereocomplexes is reported, but not significant improvement of tensile properties are observed [47]. The maximization of $\sigma_{\mathrm{y}}$ is thus essentially due to the synergy in increasing crystallinity content when both PDLA and LAK are used and will be more extensively discussed in the following.

As in the case of elastic modulus, the $\sigma_{\mathrm{y}}$ decreasing by increasing OLA8 concentration can be ascribed to the improved free volume between PLA macromolecules and increased mutual mobility of the PLA chains [36].

Concerning the stress at break $\left(\sigma_{\mathrm{b}}\right)$, which is a measure much dependent on the presence of defects in the material and less reliable than $\sigma_{\mathrm{y}}$, the coefficients and the trace plot analysis (not reported) reveal that this property is mainly influenced by OLA 8 and PLA content ( $p$-value associated to each coefficient

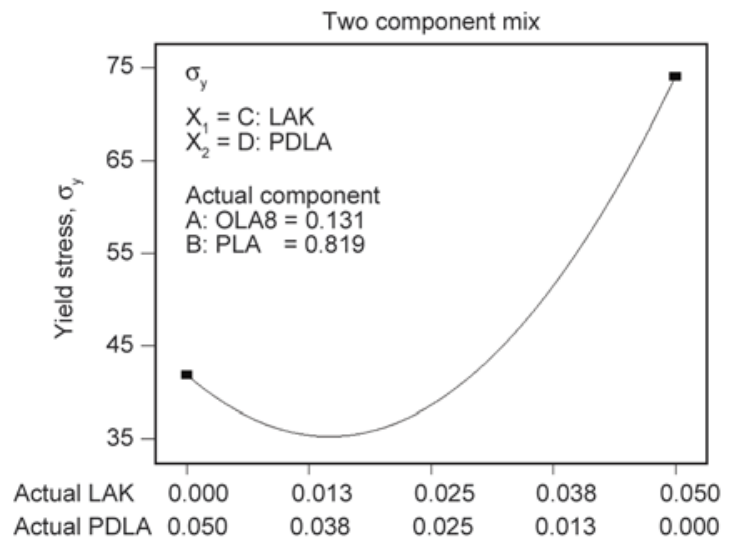

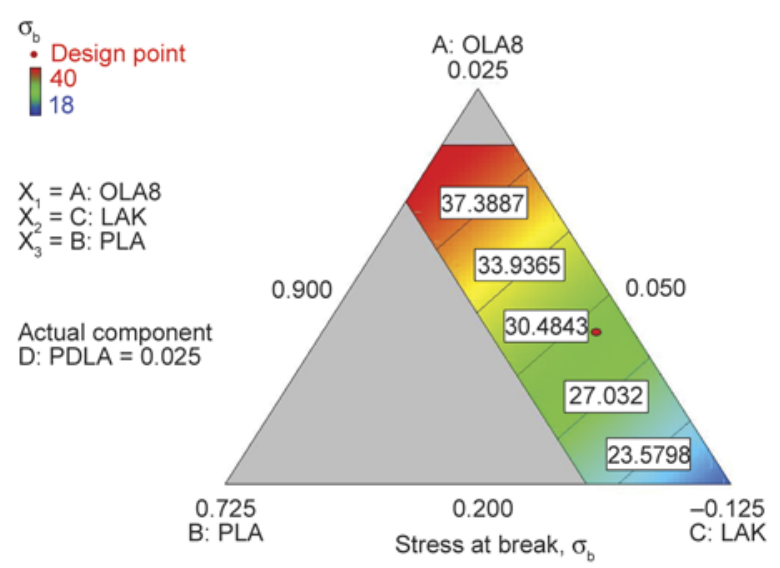

Figure 4. Contour plot of stress at break $\left(\sigma_{\mathrm{b}}\right)$

is less than 0.05) (Figure 4). Moreover, as observed for $E$, also in this case the most significant effect is played by the content of OLA 8 in the blend. On the contrary, while a very slight effect of LAK is reported, the PDLA does not produce any significant variation on $\sigma_{\mathrm{b}}$. In detail, by decreasing the OLA 8 content $\sigma b$ increases whereas a decrease in the LAK content leads to a decrease of this mechanical property.

The addition of OLA8 to PLA leads to reduction of $T_{\mathrm{g}}$ and also $E, \sigma_{\mathrm{y}}$ and $\sigma_{\mathrm{b}}$ as the normal effect of plasticization, thanks to the increased mobility of macromolecular chains at room temperature, making the material less resistant but more ductile. Interestingly $\sigma_{\mathrm{y}}$ varies monotonously with LAK concentration.

The statistical analysis for elongation at break $\varepsilon_{\mathrm{b}}$ is not reported since the model is not significant. The high values of elongation at break $(>200 \%)$ at the highest content of OLA8 (20 wt \%), are in agreement with the high miscibility of these additive with PLA $[14,15]$.

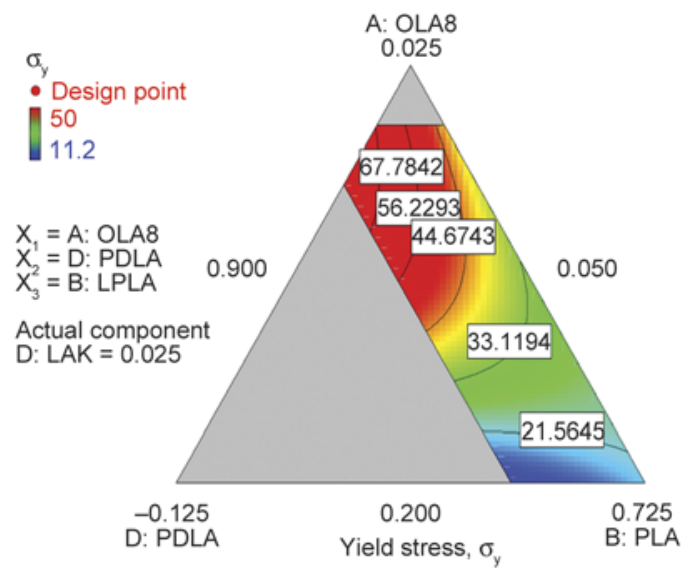

Figure 3. Two components mix graph (a) and contour plot (b) of yield stress $\left(\sigma_{\mathrm{y}}\right)$ 


\subsection{Thermal properties}

The experimental results of DSC analysis reported in Table 5 are codified in terms of time to achieve $50 \%$ crystallization at $105^{\circ} \mathrm{C}\left(t_{1 / 2}\right)$, crystallinity $\%$ determined at the first DSC scan (\% cryst I) and crystallinity $\%$ determined at the second DSC scan ( $\%$ cryst II). The glass transition temperature values, determined by DMTA tests (Table 4), were also codified as $T_{\mathrm{g}}$.

In the DSC thermograms during the heating steps (I or II run) two peaks were observed in the melting region. The first peak can be attributed to the melting of more irregular $\alpha^{6}$ crystals and the second to the more ordered $\alpha$ crystals [4].

In sample 3, without nucleating agents, there was no crystallization in isothermal treatment at $105^{\circ} \mathrm{C}$, therefore the isothermal crystallization parameters ( $t_{1 / 2}$ and $\Delta H_{\mathrm{c}} \mathrm{II}$ ) were not recorded. In this case the $t_{1 / 2}$ is higher than $1800 \mathrm{~s}$. The use of PDLA alone (run 6) result in a $t_{1 / 2}$ of $151 \mathrm{~s}$, in good agreement with the nucleating properties reported for this additive [35]. The use of LAK alone (run 7) determined the decrease of $t_{1 / 2}$ to $61 \mathrm{~s}$, showing a better efficiency of LAK with respect to PDLA as yet reported by Shi et al. [38] for PLA plasticized with PEG.

LAK and PDLA were simultaneously present in most of the prepared samples and their synergy in nucleation, yet evidenced by Shi et al. [38], is evident by comparing the first heating scan of the plasticized PLA with the two nucleating agents (St 2) and the one with only LAK (St 7) (Figure 5). In the former trend the crystallization temperature is quite lower

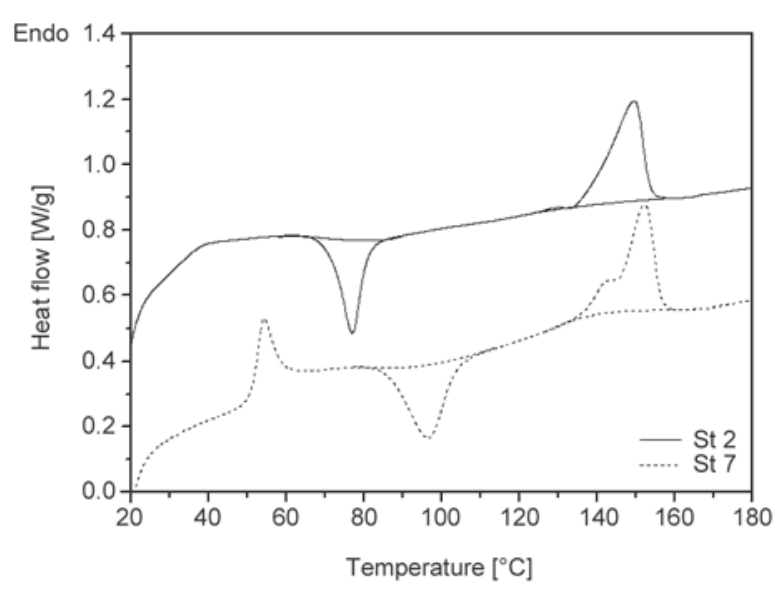

Figure 5. First heating thermogram of St 2 (with both LAK and PDLA) and St 7 (with only LAK)

than in the latter, while the crystallinity is higher (Table 5). Moreover the $t_{1 / 2}$ is $48 \mathrm{~s}$ if both LAK and PDLA are used and it is $61 \mathrm{~s}$ if only LAK is added. The presence of only PDLA (run 4) resulted in a $t_{1 / 2}$ of $112 \mathrm{~s}$. The presence of both the nucleating agents is thus necessary to increase effectively crystallization rate.

Concerning the statistical analysis it is worth noting that for $\Delta H_{\mathrm{c} \%}, \%$ cryst I and $\%$ cryst II significant models can be derived.

The experiment 5 (considered as an outlier by the residual analysis) is neglected in the $\Delta H_{\mathrm{c}}, \%$ cryst I and $\%$ cryst II statistical data analysis.

The ANOVA analysis shows that while the effect of the mixture components on $T_{\mathrm{g}}$ is well described through the linear model, for $\Delta H_{\mathrm{c}}, \%$ cryst I, $\%$ cryst. II and $t_{1 / 2}$ quadratic terms need to be

Table 5. Thermal properties of the investigated samples

\begin{tabular}{|c|c|c|c|c|c|c|c|c|c|c|c|}
\hline & \multicolumn{5}{|c|}{ I Run } & \multicolumn{2}{|c|}{ ISO $T 105^{\circ} \mathrm{C}$} & \multicolumn{4}{|c|}{ II Run } \\
\hline St & $\begin{array}{c}\Delta H_{\mathrm{c}} \mathrm{I} \\
{[\mathrm{J} / \mathrm{g}]}\end{array}$ & $\begin{array}{c}T_{\mathrm{m}_{1}} \\
{\left[{ }^{\circ} \mathbf{C}\right]}\end{array}$ & $\begin{array}{c}T_{\mathbf{m}} \\
{\left[{ }^{\circ} \mathbf{C}\right]}\end{array}$ & $\begin{array}{c}\boldsymbol{T}_{\mathbf{c}} \\
{\left[{ }^{\circ} \mathbf{C}\right]}\end{array}$ & $\%$ cryst. I & $\begin{array}{l}t_{1 / 2} \\
{[\mathrm{~s}]}\end{array}$ & $\underset{[\mathbf{J} / \mathbf{g}]}{\Delta H_{\mathrm{c}} \mathbf{I I}}$ & $\begin{array}{c}\Delta \boldsymbol{H} \\
{[\mathbf{J} / \mathbf{g}]}\end{array}$ & $\begin{array}{c}T_{\mathrm{m}_{1}} \\
{\left[{ }^{\circ} \mathbf{C}\right]}\end{array}$ & $\begin{array}{c}T_{\mathbf{m}} \\
{\left[{ }^{\circ} \mathbf{C}\right]}\end{array}$ & \% cryst. II \\
\hline 1 & 0.25 & 134 & 152 & 87 & 0.3 & 51 & 32.5 & 21.5 & 140 & 151 & 23.1 \\
\hline 2 & 6.1 & 130 & 150 & 77 & 6.5 & 48 & 14.0 & 14.7 & 140 & 150 & 15.9 \\
\hline 3 & 1.5 & 141 & 155 & 97 & 1.6 & n. d. & n. d. & 23.4 & 144 & 154 & 25.1 \\
\hline 4 & 0.2 & 140 & 153 & 87 & 0.3 & 112 & 41.0 & 21.3 & 142 & 153 & 22.9 \\
\hline 5 & 6.8 & 136 & 152 & 76 & 7.3 & 46 & 18.0 & 12.2 & 140 & 151 & 13.1 \\
\hline 6 & 4.0 & 133 & 152 & 84 & 4.3 & 151 & 50.6 & 20.7 & 140 & 151 & 22.2 \\
\hline 7 & 3.9 & 143 & 152 & 97 & 4.2 & 61 & 20.5 & 16.2 & 145 & 153 & 17.4 \\
\hline 8 & 3.0 & 141 & 153 & 94 & 3.3 & 60 & 24.5 & 19.6 & 145 & 153 & 21.1 \\
\hline 9 & 4.4 & 144 & 155 & 98 & 4.7 & 152 & 56.2 & 23.2 & 146 & 155 & 24.9 \\
\hline 10 & 2.6 & 145 & 155 & 100 & 2.8 & 76 & 16.0 & 21.1 & 147 & 155 & 22.7 \\
\hline 11 & 3.2 & 137 & 153 & 91 & 4.6 & 38 & 19.0 & 22.5 & 143 & 154 & 24.1 \\
\hline 12 & 4.3 & 136 & 152 & 90 & 4.6 & 40 & 20.3 & 22.2 & 143 & 153 & 23.8 \\
\hline 13 & 7.9 & 138 & 158 & 91 & 4.5 & 45 & 20.0 & 21.4 & 144 & 153 & 22.9 \\
\hline 14 & 5.1 & 136 & 152 & 88 & 4.5 & 44 & 23.0 & 20.4 & 142 & 152 & 21.9 \\
\hline 15 & 5.1 & 138 & 153 & 90 & 4.5 & 41 & 20.5 & 22.5 & 143 & 153 & 24.2 \\
\hline 16 & 4.3 & 132 & 150 & 83 & 4.5 & 152 & 45.7 & 21.4 & 139 & 150 & 23.0 \\
\hline
\end{tabular}


included to improve the goodness of the models. In particular LAK*PLA for both $\%$ cryst II and $\Delta H_{\mathrm{c}}$, OLA $8 *$ PLA, OLA $8 *$ LAK, PLA*LAK, LAK*PDLA for $\%$ cryst I and OLA8*PLA, OLA $8 *$ LAK, OLA $*$ LAK, OLA $8 *$ PDLA, PLA*PDLA for $t_{1 / 2}$. The models are consistent ( $p$-values of the $F$-test $<$ $0.05)$, the Lack of Fit is not significant and the model parameters (Table 6) reveal a good fitting and predictive power, except for $t_{1 / 2}$ for which a high difference between $R$-Squared and Pred $R$-squared $(0.38)$ and data clusters were observed.

The normal distribution of the residuals for the investigated properties satisfy the statistical requirements and therefore are not reported here. Only for the $t_{1 / 2}$ the residual analysis suggests the presence of a fair normal distribution anyway the high values of $R$-Squared (0.99) and Adj R-Squared (0.99), together with an insignificant Lack of Fit, allow us to use the obtained model to explore the possible region of interest, as suggested in other works [43].

The coefficients analysis and the trace and contour plots for the $T_{\mathrm{g}}$ reported in Figures $6 \mathrm{a}$ and $6 \mathrm{~b}$ suggests that OLA8 and PLA are significant factors in defining the $T_{\mathrm{g}}$ trend. In particular an increase in OLA 8 leads to a decrease of $T_{\mathrm{g}}$ while an almost neg- ligible similar effect of LAK was observed. The glass transition temperature value is thus mainly affected by OLA8 plasticization, increasing the mobility of macromolecular chains and thus reducing the temperature at which the flexible amorphous material can be converted in a rigid amorphous glass.

LAK and OLA 8 concentrations play a moderate effect on $\%$ cryst. II and $\Delta H_{\mathrm{c}}$ (Figure 7 and Figure 8): decreasing OLA8 and LAK content leads to the increase of both the properties notwithstanding the effect of LAK is lower with respect to that produced by OLA8. These results show that when the material is annealed for long time at $105^{\circ} \mathrm{C}$, the presence of LAK does not lead to crystallinity increase. These results confirm that the effect of a nucleating agent is increasing the nuclei density, but as the number of nuclei is increased, for long annealing time, the crystal growth is limited, leading to crystallinity decrease with respect to not nucleated PLA. This effect was noticed for many other nucleation agents [4]. In a similar way the presence of plasticizer on one side increases the mobility of the chains favouring the crystalline packing, but on the other side introduces disorder in the system, partially replacing intermacromolecular interactions, significant for crystals

Table 6. ANOVA results for the thermal properties glass transition temperature $\left(T_{\mathrm{g}}\right)$, crystallization enthalpy $\left(\Delta H_{\mathrm{c}}\right)$ and percent crystallinity ( $\%$ cryst. I and $\%$ cryst. II) and crystallization half-time $\left(t_{1 / 2}\right)$

\begin{tabular}{|c|c|c|c|c|c|c|c|}
\hline & F-value & $p$-value ${ }^{a}$ & Lack of fit & $p$-value ${ }^{b}$ & R-Squared & Adj R-Squared & Pred R-Squared \\
\hline$T_{\mathrm{g}}$ & 108.6 & $<0.0001$ & 0.67 & 0.70 & 0.96 & 0.95 & 0.93 \\
\hline$\Delta H_{\mathrm{c}}$ & 23.7 & $<0.0001$ & 1.18 & 0.43 & 0.90 & 0.87 & 0.82 \\
\hline$\%$ Cryst. I & 31.9 & $<0.0001$ & 0.94 & 0.45 & 0.97 & 0.87 & 0.94 \\
\hline \% Cryst. II & 23.7 & $<0.0001$ & 1.17 & 0.43 & 0.90 & 0.88 & 0.82 \\
\hline$t_{1 / 2}$ & 491.39 & $<0.0001$ & 1.15 & 0.33 & 0.99 & 0.99 & 0.61 \\
\hline
\end{tabular}

${ }^{\mathrm{a}} p$-value associated to the F-Test of the regression model

${ }^{\mathrm{b}} \mathrm{p}$-value associated to the lack of fit test
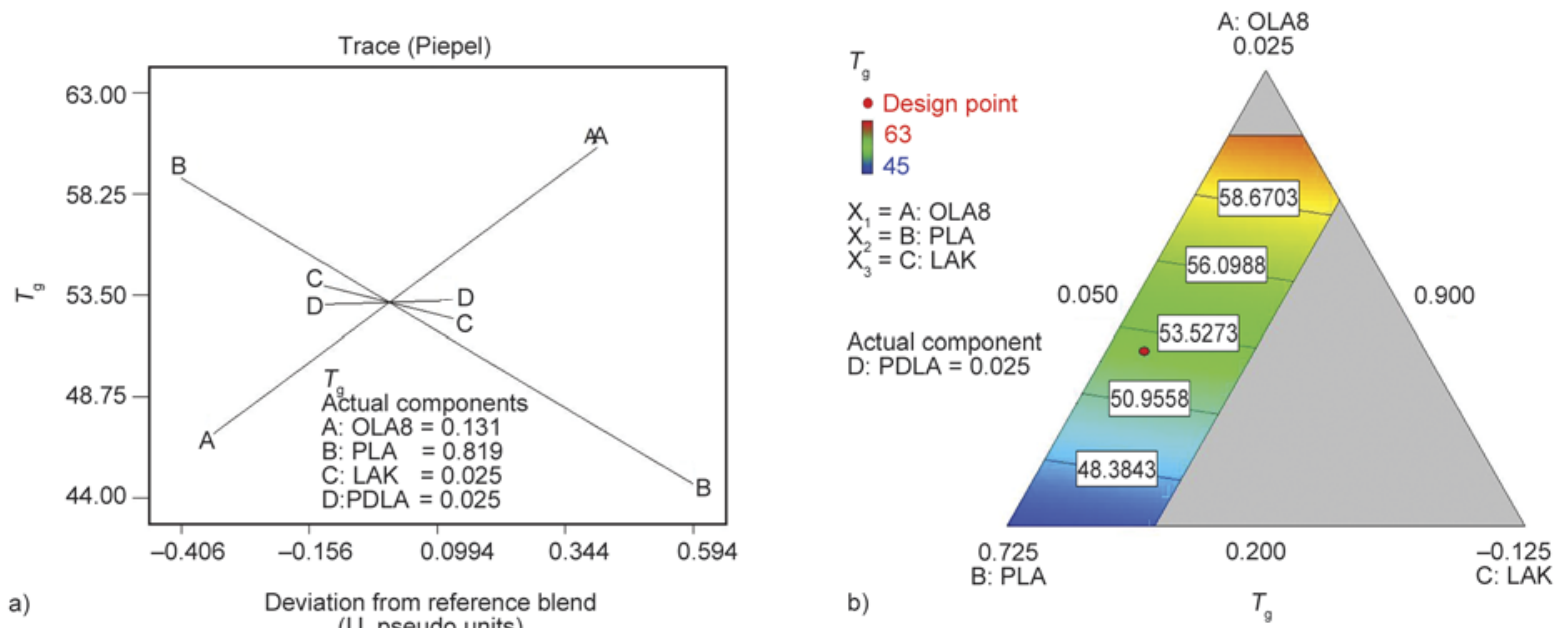

(U_pseudo units)

Figure 6. Trace (a) and contour plots (b) of glass transition temperature $\left(T_{\mathrm{g}}\right)$ 


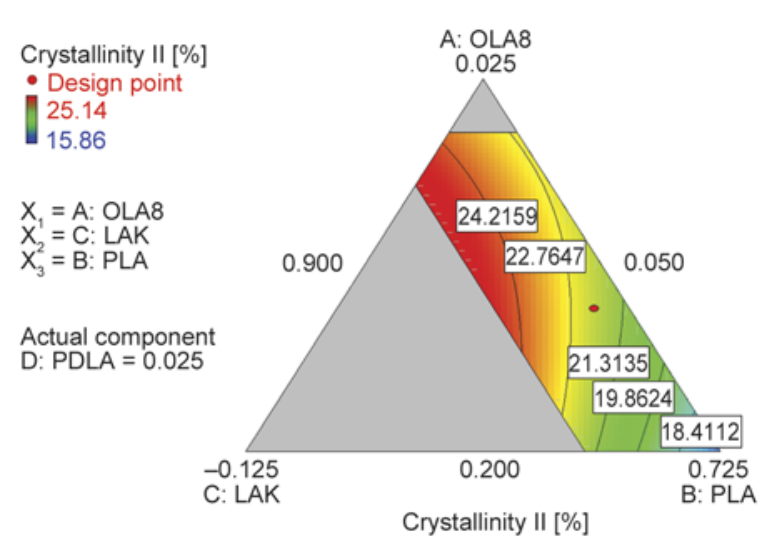

Figure 7. Contour plot of \% Cryst. II

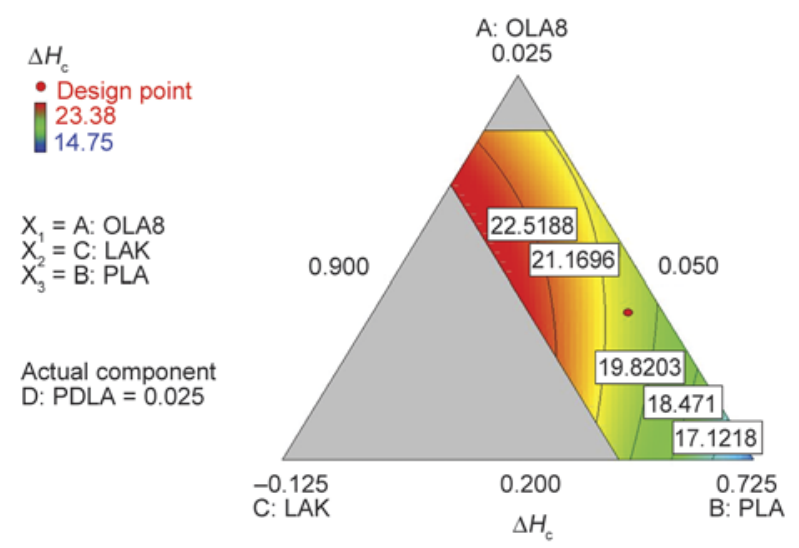

Figure 8. Contour plot of crystallization enthalpy $\Delta H_{\mathrm{c}}$

formation, with plasticizer-macromolecule ones. In the specific case of OLA8 the introduction of disorder is given by the presence of the terminal groups, as the chain structure is the same as PLA. Thermodynamic driving forces thus predominate on kinetic ones. This explains why for high annealing time the crystallinity decreases as a function of OLA 8 content [32].

Differently, changes in PDLA content do not produce any variation of $\%$ cryst. II and $\Delta H_{\mathrm{c}}$.

The analysis of the crystallization half-time $\left(t_{1 / 2}\right)$ shows that all terms, including the interaction ones, cover an important role in the variation of this property. From the trace plot (not showed) it was observed that both LAK and PDLA can contribute to a $t_{1 / 2}$ variation with a parabolic trend. From the low to the intermediate concentration of LAK the crystallization half-time decreases, but the further increase of LAK leads to an increase of $t_{1 / 2}$. PDLA has an opposite effect with respect to LAK. Moreover, it is worth noting that the region in which the crystallization half-time is at the minimum level, underlined in the contour plot in Figure 9, is the one in which significant crystallinity can be developed more rapidly.

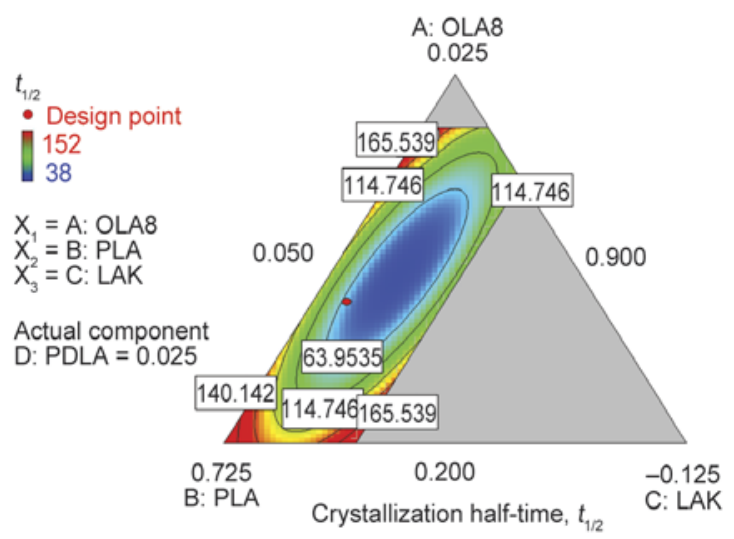

Figure 9. Contour plot of crystallization half-time $t_{1 / 2}$

On this trend a strong responsibility is played by the non-linear terms such as the OLA8*LAK: modifying this factor allows achieving the lower $t_{1 / 2}$ values.

The synergistic effect of plasticizer and nucleation agent in increasing the crystallization rate was already suggested and reported in literature but the important value added by this work derive by the definition of a specific region in which this synergy occurs. Hence, this study allows the understanding of the role played by each components and their mutual interaction on the $t_{1 / 2}$ decreasing $[24,32-33,46]$. The synergy of OLA8 and LAK plays a key role in the crystallization rate properties of the mixture and in particular, an intermediate concentration with respect of the explored range encounters the condition of maximum crystallization rate. In this peculiar range the optimal concentration of LAK to determine the increase of nuclei density is reached and the further addition of LAK is detrimental with respect to heterogeneous nucleation. On the other side an intermediate value of OLA8 content is required to minimize $t_{1 / 2}$. As the plasticizer is reported to increase the spherulitic growth rate [32] thanks to the increased mobility, we can observe that probably a high concentration of it introduces excessive dilution of macromolecular PLA chains in the system, thus limiting the growth rate. In the composition range where the minimum $t_{1 / 2}$ is found the correct balance between formation of nuclei rate and spherulitic growth rate can be found.

Since the development of crystallinity in its early stage covers a fundamental role during processing, especially during injection moulding, the $\%$ cryst. I (Figure 10), developed during the cooling in the injection molding press, represents a quite interesting technological parameter. The rapid development of crystallinity can allow the rapid development of 

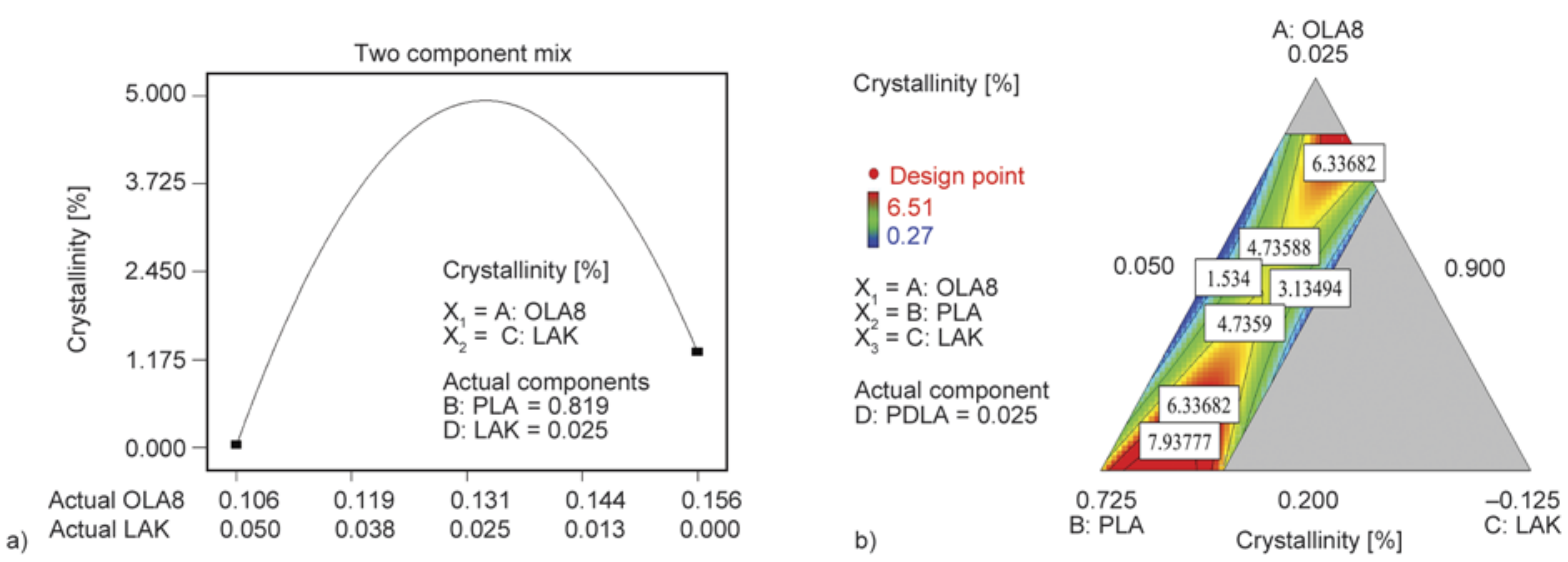

Figure 10. (a) Two components mix graph and (b) contour plot of \% Cryst. I

mechanical resistance and the easy removal of the injection molded part from the mould assuring a short industrial cycle. Among the linear terms LAK displays the most important role, and its effect can be described considering that moving from the maximum to the intermediate value (while maintaining constant the ratio between the other components) an increase of the $\%$ cryst. I can be observed. On the contrary, further decrease in the LAK content (moving to the minimum value) leads to a decrease in the $\%$ cryst. I.

In agreement with $t_{1 / 2}$ results, an intermediate content of LAK with respect to the explored range can assure the highest content of crystallinity, probably thanks to the same capacity of increasing nuclei density up to an optimal concentration.

Concerning the crystallinity of the mixture a quite different trend is observed with respect to \% Cryst. II. In fact a parabolic trend with a minimum was observed as a function of OLA8 content: the highest value of \% Cryst. I is achieved when the content of plasticizer is the highest. This effect is in contrast with the trend observed for the use of only a plasticizer in PLA, because usually the crystallinity developed during rapid cooling increases by increasing the plasticizer content $[16,29,30]$. In this case is the heterogeneity introduced by the plasticizer in nucleating crystals. This is in agreement with the recent use of miscible polymers as nucleating agents [20]. On the other hand, in the presence of a nucleating agent the beginning of crystals growth occurs starting on the nuclei surface. When the concentration of plasticizer is low (up to 10\%), it hinders the crystal growth with respect to pure PLA. As the chemical structure of OLA 8 is identical to the one of PLA, this action is certainly attributable to the higher concentration of terminals, creating local disorder and thus disabling crystal packing close to nucleating agent surface. It is possible to hypothesize that the terminal groups are more concentrated close to the nucleating agent surface because of the attraction between the terminal groups of OLA and the polar groups on the LAK particles surface. On the contrary, when the concentration is high the main effect of OLA8 is allowing the spatial separation of macromolecules providing a higher free volume for segments motions, allowing the chains fragments to assemble in crystals more easily. Hence the plasticizer, which was reported to favour in general crystal growth [32], is found here to disturb crystal growth in the early stage of crystal formation if present at intermediate concentration and to favour it if present at high concentration. Hence during the rapid cooling below glass transition the availability of free volume is confirmed to be a factor that improves crystal growth rate on a kinetic point of view but only at high OLA8 content.

\subsection{Comparison between thermal and mechanical data}

Thermal data related to the first DSC heating step and mechanical data can be correlated as resulting from testing on specimens underwent to identical thermal treatment. The application of the Mixture Design approach to PLA containing a plasticizer and two different nucleating agents evidenced that the mechanical properties, such as $E, \sigma_{\mathrm{b}}$ and $\sigma_{\mathrm{y}}$ decreased by increasing OLA8 because of plasticization. On the other hand the crystallinity \% Cryst. I correspondingly showed a minimum-like trend. However the crystallinity content of the sample developed in the cold mould at $35^{\circ} \mathrm{C}$ is quite low. If we consider the semi-crystalline PLA as a particulate composite consisting in an amorphous matrix with 
dispersed crystalline domains, we can consider that (Equation (5)):

$\sigma_{\mathrm{b}}=\sigma_{\text {cryst }} V_{\text {cryst }}+\sigma_{\text {amor }} V_{\text {amor }}$

where $\sigma_{\mathrm{b}}$ is the measured stress at break of PLA and $\sigma_{\text {cryst }}, V_{\text {cryst }}, \sigma_{\text {amor }}$ and $V_{\text {amor }}$ are the stress at break and volume fractions of its crystalline and amorphous phases, respectively. We have to notice that Equation (5) represents a strong approximation, since $\sigma_{\text {cryst }} V_{\text {cryst }}$ is probably the sum of contributions of two different kinds of crystals: $\alpha$ and $\alpha^{\prime}$. In fact both kinds of crystals are present, as revealed by DSC analysis. However, as the material is mainly amorphous (in fact the crystallinity varies in the range $0.3-7.3 \%$ ) in this case the mechanical properties strongly depend on the rigidity of the amorphous phase. In fact the elastic modulus of the amorphous phase, as well as the $T_{\mathrm{g}}$ value, decreases as the OLA8 content increases. This can easily explain the trend of $E, \sigma_{\mathrm{y}}$ and $\sigma_{\mathrm{b}}$ as a function of OLA8 content.

On the other hand $E, \sigma_{\mathrm{b}}$ and $\sigma_{\mathrm{y}}$ were found to increase with LAK content whereas the \% Cryst. I crystallinity showed a maximum at about $3 \%$ LAK. The trend can be explained again keeping into account that mechanical properties are mainly consequence of the rigidity of the amorphous phase. In this case, we can consider the interaction of LAK or small LAK aggregates with PLA macromolecules, acting as physical cross-linking points, thus resulting in an increased modulus of the amorphous matrix. In accordance this can explain why $E, \sigma_{\mathrm{b}}$ and $\sigma_{\mathrm{y}}$ increase upon increasing LAK concentration.

\section{Conclusions}

The application of a Mixture Design approach allowed investigating the influence of plasticization and nucleation onto thermal behaviour and mechanical properties of PLA based materials in a systematic way, by clearly identifying composition regions where the crystallization rate is maximized and where a synergistic effect can be observed between plasticizer and nucleation agents, attributed to the optimization of balance between formation of nuclei rate and spherulitic growth rate. LAK resulted efficient as nucleating agent since the half time of crys- tallization of PLA in the blends with LAK and PDLA was significantly reduced.

Interestingly the crystallinity developed during injection moulding resulted maximized at intermediate LAK content with respect to the investigated range, whereas it presents a minimum-like trend as a function of OLA8 concentration. Hence the plasticizer, which was reported to favour in general crystal growth [32], is found here to disturb crystal growth in the early stage of crystal formation if present in intermediate concentration and to favour it if present at higher concentration.

However the mechanical properties were found to be mainly dependent on the amorphous phase rigidity of the PLA based compounds as the crystallinity content developed was low, in the range $0,3-7,3 \%$ in the experimented conditions. Hence $E, \sigma_{\mathrm{b}}$ and $\sigma_{\mathrm{y}}$ were found to increase as a function of LAK content increase and decrease as a function of OLA8 increase. The former trend was attributed to specific interaction between LAK and PLA macromolecules improving amorphous phase rigidity and the latter can be attributed to reduction of amorphous phase rigidity thanks to plasticization.

The technological exploitation of this study can occur by correctly modifying mould temperature (close to cold crystallization temperature) and holding time (it should be increased) in injection moulding to benefit of the improved crystallization rate in the composition range where a synergy between plasticization and nucleation was found. In the case of fast cooling below glass transition temperature (condition experimented in the present work) this study demonstrates that the developed crystallinity is quite low, but can be maximized by using intermediate concentration of LAK and a high content of OLA8, to find, even in these less favourable conditions for crystallization, the best compromise between the increase of nuclei density due to LAK and the increase of spherulite growth rate due to OLA8.

\section{Acknowledgements}

Authors acknowledge the financial support from the European Union's Seventh Framework Programme, DIBBIOPACK [Development of injection and extrusion blow moulded biodegradable and multifunctional packages by nanotechnologies GA: $n^{\circ} 280676$.] 


\section{References}

[1] Liu H., Zhang J.: Research progress in toughening modification of poly(lactic acid). Journal of Polymer Science Part B: Polymer Physics, 49, 1051-1083 (2011). DOI: 10.1002/polb.22283

[2] Lim L-T., Auras R., Rubino M.: Processing technologies for poly(lactic acid). Progress in Polymer Science, 33, 820-852 (2008).

DOI: $10.1016 /$ j.progpolymsci.2008.05.004

[3] Auras R., Harte B., Selke S.: An overview of polylactides as packaging materials. Macromolecular Bioscience, 4, 835-864 (2004).

DOI: $10.1002 /$ mabi.200400043

[4] Saeidlou S., Huneault M. A., Li H., Park C. B.: Poly(lactic acid) crystallization. Progress in Polymer Science, 37, 1657-1677 (2012).

DOI: 10.1016/j.progpolymsci.2012.07.005

[5] Garlotta D.: A literature review of poly(lactic acid). Journal of Polymers and the Environment, 9, 63-84 (2001). DOI: 10.1023/A:1020200822435

[6] Kister G., Cassanas G., Vert M.: Effects of morphology, conformation and configuration on the IR and Raman spectra of various poly(lactic acid)s. Polymer, 39, 267273 (1998).

DOI: 10.1016/S0032-3861(97)00229-2

[7] Coltelli M-B., Bronco S., Chinea C.: The effect of free radical reactions on structure and properties of poly(lactic acid) (PLA) based blends. Polymer Degradation and Stability, 95, 332-341 (2010).

DOI: $10.1016 /$ j.polymdegradstab.2009.11.015

[8] Nerkar M., Ramsay J. A., Ramsay B. A., Vasileiou A. A., Kontopoulou M.: Improvements in the melt and solidstate properties of poly(lactic acid), poly-3-hydroxyoctanoate and their blends through reactive modification. Polymer, 64, 51-61 (2015).

DOI: 10.1016/j.polymer.2015.03.015

[9] Raquez J-M., Habibi Y., Murariu M., Dubois P.: Polylactide (PLA)-based nanocomposites. Progress in Polymer Science, 38, 1504-1542 (2013).

DOI: 10.1016/j.progpolymsci.2013.05.014

[10] Kowalczyk M., Piorkowska E., Kulpinski P., Pracella M.: Mechanical and thermal properties of PLA composites with cellulose nanofibers and standard size fibers. Composites Part A: Applied Science and Manufacturing, 42, 1509-1514 (2011).

DOI: $10.1016 /$ j.compositesa.2011.07.003

[11] Pluta M., Paul M-A., Alexandre M., Dubois P.: Plasticized polylactide/clay nanocomposites. I. The role of filler content and its surface organo-modification on the physico-chemical properties. Journal of Polymer Science Part B: Polymer Physics, 44, 299-311 (2006). DOI: $10.1002 /$ polb.20694
[12] Scatto M., Salmini E., Castiello S., Coltelli M-B., Conzatti L., Stagnaro P., Andreotti L., Bronco S.: Plasticized and nanofilled poly(lactic acid)-based cast films: Effect of plasticizer and organoclay on processability and final properties. Journal of Applied Polymer Science, 127, 4947-4956 (2013).

DOI: 10.1002/APP.38042

[13] Hassouna F., Raquez J-M., Addiego F., Dubois P., Toniazzo V., Ruch D.: New approach on the development of plasticized polylactide (PLA): Grafting of poly (ethylene glycol) (PEG) via reactive extrusion. European Polymer Journal, 47, 2134-214 (2011).

DOI: $10.1016 /$ j.eurpolymj.2011.08.001

[14] Burgos N., Tolaguera D., Fiori S., Jimenez A.: Synthesis and characterization of lactic acid oligomers: Evaluation of performance as poly(lactic acid) plasticizers. Journal of Polymers and the Environment, 22, 227235 (2014).

DOI: $10.1007 / \mathrm{s} 10924-013-0628-5$

[15] Burgos N., Martino V. P., Jiménez A.: Characterization and ageing study of poly(lactic acid) films plasticized with oligomeric lactic acid. Polymer Degradation and Stability, 98, 651-658 (2013).

DOI: 10.1016/j.polymdegradstab.2012.11.009

[16] Coltelli M-B., Della Maggiore I., Bertoldo M., Bronco S., Signori F., Ciardelli F.: Poly(lactic acid) properties as a consequence of poly(butylene adipate-co-terephthalate) blending and acetyl tributyl citrate plasticization. Journal of Applied Polymer Science, 110, 12501262 (2008).

DOI: $10.1002 / a p p .28512$

[17] Quero E., Müller A. J., Signori F., Coltelli M-B., Bronco S.: Isothermal cold-crystallization of PLA/PBAT blends with and without the addition of acetyl tributyl citrate. Macromolecular Chemistry and Physics, 213, 36-48 (2012).

DOI: $10.1002 /$ macp.201100437

[18] Nagarajan V., Zhang K., Misra M., Mohanty A. K.: Overcoming the fundamental challenges in improving the impact strength and crystallinity of PLA biocomposites: Influence of nucleating agent and mold temperature. ACS Applied Material Interfaces, 7, 11203-11214 (2015).

DOI: $10.1021 /$ acsami.5b01145

[19] Wang L., Wang Y-N., Huang Z-G., Weng Y-X.: Heat resistance, crystallization behavior, and mechanical properties of polylactide/nucleating agent composites. Materials and Design, 66, 7-15 (2015).

DOI: $10.1016 /$ j.matdes.2014.10.011

[20] Guo X., Liu H., Zhang J., Huang J.: Effects of polyoxymethylene as a polymeric nucleating agent on the isothermal crystallization and visible transmittance of poly(lactic acid). Industrial and Engineering Chemistry Research, 53, 16754-16762 (2014).

DOI: $10.1021 / \mathrm{ie} 502104 \mathrm{y}$ 
[21] Penco M., Spagnoli G., Peroni I., Rahman W. A., Frediani M., Oberhauser W., Lazzeri A.: Effect of nucleating agents on the molar mass distribution and its correlation with the isothermal crystallization behavior of poly (L-lactic acid). Journal of Applied Polymer Science, 122, 3528-3536 (2011).

DOI: $10.1002 /$ app.34761

[22] Nam J. Y., Okamoto M., Okamoto H., Nakano M., Usuki A., Matsuda M.: Morphology and crystallization kinetics in a mixture of low-molecular weight aliphatic amide and polylactide. Polymer, 47, 1340-1347 (2006). DOI: 10.1016/j.polymer.2005.12.066

[23] Ma P., Xu Y., Wang D., Dong W., Chen M.: Rapid crystallization of poly(lactic acid) by using tailor-made oxalamide derivatives as novel soluble-type nucleating agents. Industrial and Engineering Chemistry Research, 53, 12888-12892 (2014). DOI: $10.1021 / \mathrm{ie} 502211 \mathrm{j}$

[24] Battegazzore D., Bocchini S., Frache A.: Crystallization kinetics of poly(lactic acid)-talc composites. Express Polymer Letters, 5, 849-858 (2011). DOI: $10.3144 /$ expresspolymlett.2011.84

[25] Ouchiar S., Stoclet G., Cabaret C., Georges E., Smith A., Martias C., Addad A., Gloaguen V.: Comparison of the influence of talc and kaolinite as inorganic fillers on morphology, structure and thermomechanical properties of polylactide based composites. Applied Clay Science, 116-117, 231-240 (2015).

DOI: $10.1016 /$ j.clay.2015.03.020

[26] Blaker J. J., Lee K-Y., Walters M., Drouet M., Bismarck A.: Aligned unidirectional PLA/bacterial cellulose nanocomposite fibre reinforced PDLLA composites. Reactive and Functional Polymers, 85, 185-192 (2014).

DOI: $10.1016 /$ j.reactfunctpolym.2014.09.006

[27] Chen C., He B-X., Wang S-L., Yuan G-P., Zhang L.: Unexpected observation of highly thermostable transcrystallinity of poly(lactic acid) induced by aligned carbon nanotubes. European Polymer Journal, 63, 177185 (2015).

DOI: $10.1016 /$ j.eurpolymj.2014.12.012

[28] Liang Y-Y., Yang S., Jiang X., Zhong G-J., Xu J-Z., Li Z-M.: Nucleation ability of thermally reduced graphene oxide for polylactide: Role of size and structural integrity. The Journal of Physical Chemistry B, 119, 4777-4787 (2015).

DOI: $10.1021 /$ jp511742b

[29] Pluta M.: Morphology and properties of polylactide modified by thermal treatment, filling with layered silicates and plasticization. Polymer, 45, 8239-8251 (2004).

DOI: 10.1016/j.polymer.2004.09.057

[30] Xiao H., Yang L., Ren X., Jiang T., Yeh J. T.: Kinetics and crystal structure of poly(lactic acid) crystallized nonisothermally: Effect of plasticizer and nucleating agent. Polymer Composites, 31, 2057-2068 (2010).

DOI: $10.1002 /$ pc. 21004
[31] You J., Yu W., Zhou C.: Accelerated crystallization of poly(lactic acid): Synergistic effect of poly(ethylene glycol), dibenzylidene sorbitol, and long-chain branching. Industrial and Engineering Chemistry Research, 53, 1097-1107 (2014). DOI: 10.1021/ie402358h

[32] Yu L., Liu H., Dean K., Chen L.: Cold crystallization and postmelting crystallization of PLA plasticized by compressed carbon dioxide. Journal of Polymer Science Part B: Polymer Physics, 46, 2630-2636 (2008). DOI: $10.1002 /$ polb.21599

[33] Li H., Huneault M. A.: Effect of nucleation and plasticization on the crystallization of poly(lactic acid). Polymer, 48, 6855-6866 (2007).

DOI: $10.1016 /$ j.polymer.2007.09.020

[34] Anderson K. A., Randall J. R., Kolstad J. J.: Polylactide molding compositions and molding process. Nature Word Patent, WO 2011085058 A1 (2011).

[35] Wei X-F., Bao R-Y., Cao Z-Q., Zhang L-Q., Liu Z-Y., Yang W., Xie B-H., Yang M-B.: Greatly accelerated crystallization of poly(lactic acid): Cooperative effect of stereocomplex crystallites and polyethylene glycol. Colloid and Polymer Science, 292, 163-172 (2014). DOI: $10.1007 / \mathrm{s} 00396-013-3067-\mathrm{x}$

[36] Tsuji H., Ikada Y.: Stereocomplex formation between enantiomeric poly(lactic acid)s. XI. Mechanical properties and morphology of solution-cast films. Polymer, 40, 6699-6708 (1999). DOI: 10.1016/S0032-3861(99)00004-X

[37] Lopez-Rodriguez N., de Arenaza I. M., Meaurio E., Sarasua J. R.: Improvement of toughness by stereocomplex crystal formation in optically pure polylactides of high molecular weight. Journal of the Mechanical Behavior of Biomedical Materials, 37, 219-225 (2014).

DOI: $10.1016 / \mathrm{j} . j m b b m .2014 .05 .022$

[38] Shi X., Zhang G., Phuong T. V., Lazzeri A.: Synergistic effects of nucleating agents and plasticizers on the crystallization behavior of poly(lactic acid). Molecules, 20, 1579-1593 (2015).

DOI: $10.3390 /$ molecules20011579

[39] Eriksson L., Johansson E., Kettaneh-Wold N., Wikström C., Wold S.: Design of experiments, principle and applications. Umetrics Academy, Stockholm (2008).

[40] Montgomery D. C.: Design and analysis of experiments. Wiley, New York (2001).

[41] Tee Y. B., Talib R. A., Abdan K., Chin N. L., Basha R. K., Yunos K. F. M.: Thermally grafting aminosilane onro kenaf-derived cellulose and its influence on the thermal properties of poly(lactic acid) composites. BioResources, 8, 4468-4483 (2013).

[42] Scheffé H.: Experiments with mixtures. Journal of the Royal Statistical Society, 20, 344-360 (1958). 
[43] Akalin O., Akay K. U., Sennaroglu B., Tez M.: Optimization of chemical admixture for concrete on mortar performance tests using mixture experiments. Chemometrics and Intelligent Laboratory Systems, 104, 233 242 (2010).

DOI: $10.1016 /$ j.chemolab.2010.08.013

[44] Nam B. U., Lee B. S., Kim M. H., Hong C. H.: Effect of a nucleating agent on crystallization behavior and mechanical property of PLA stereocomplex. in 'ICCM18 proceedings, Jeju, Korea' p.4 (2011).

[45] Nam B-U., Lee B-S.: Toughening of PLA stereocomplex by impact modifiers. Journal of the Korea Academia-Industrial Cooperation Society, 13, 919-925 (2012). DOI: 10.5762/KAIS.2012.13.2.919
[46] Jing Z., Shi X., Zhang G., Li J.: Rheology and crystallization behavior of PLLA/TiO 2 -g-PDLA composites. Polymers for Advanced Technologies, 26, 528-537 (2015). DOI: $10.1002 /$ pat.3485

[47] Phuphuak Y., Miao Y., Zinck P., Chirachanchai S.: Balancing crystalline and amorphous domains in PLA through star-structured polylactides with dual plasticizer/nucleating agent functionality. Polymer, 54, 70587070 (2013).

DOI: $10.1016 /$ j.polymer.2013.10.006 